\title{
THE JOURNAL OF PHYSICAL CHEMISTRY
}

Subscriber access provided by Université de Strasbourg - Service Commun de la Documentation

\section{C: Energy Conversion and Storage; Energy and Charge Transport}

\section{Effects of Native Vacancies in Nb Doped MgH Using DFT Calculations}

Francisco Gaztañaga, Carla Romina Luna, Valeria Orazi, Estela Andrea González, Ricardo Faccio, and Paula V. Jasen

J. Phys. Chem. C, Just Accepted Manuscript • DOI: 10.1021/acs.jpcc.8b09857 • Publication Date (Web): 10 Nov 2018

Downloaded from http://pubs.acs.org on November 13, 2018

\section{Just Accepted}

"Just Accepted" manuscripts have been peer-reviewed and accepted for publication. They are posted online prior to technical editing, formatting for publication and author proofing. The American Chemical Society provides "Just Accepted" as a service to the research community to expedite the dissemination of scientific material as soon as possible after acceptance. "Just Accepted" manuscripts appear in full in PDF format accompanied by an HTML abstract. "Just Accepted" manuscripts have been fully peer reviewed, but should not be considered the official version of record. They are citable by the Digital Object Identifier (DOI®). "Just Accepted" is an optional service offered to authors. Therefore, the "Just Accepted" Web site may not include all articles that will be published in the journal. After a manuscript is technically edited and formatted, it will be removed from the "Just Accepted" Web site and published as an ASAP article. Note that technical editing may introduce minor changes to the manuscript text and/or graphics which could affect content, and all legal disclaimers and ethical guidelines that apply to the journal pertain. ACS cannot be held responsible for errors or consequences arising from the use of information contained in these "Just Accepted" manuscripts. 


\title{
Effects of Native Vacancies in $\mathrm{Nb}$ doped $\mathrm{MgH}_{2}$ Using DFT Calculations
}

\author{
Francisco Gaztañaga ${ }^{1}$, C. Romina Luna ${ }^{1}$, Valeria Orazi ${ }^{2}$, Estela González ${ }^{1}$, Ricardo Faccio ${ }^{3}$, Paula \\ Jasen $^{1 *}$ \\ ${ }^{1}$ Instituto de Física del Sur - IFISUR, UNS-CONICET y Departamento de Física, Universidad Nacional del \\ Sur, Av. Alem 1253, B8000CPB, Bahía Blanca, Argentina. \\ 2 Instituto de Física del Sur - IFISUR, UNS-CONICET y Departamento de Eléctrica y de Computadoras, \\ Universidad Nacional del Sur, Av. Alem 1253, B8000CPB, Bahía Blanca, Argentina. \\ ${ }^{3}$ Centro NanoMat - Física - DETEMA - Facultad de Química, Universidad de la República, Av. Gral. Flores \\ 2124, 11800, Montevideo, Uruguay.
}

\section{*Corresponding Author:}

Dr. Paula V. Jasen

Telephone: +54 (0291) 4595101 ext: 2843

E-mail address: pjasen@uns.edu.ar

Postal address: Departamento de Física and Instituto de Física del Sur (UNS-CONICET), Av. Alem 1253, 8000, Bahía Blanca, Argentina. 


\begin{abstract}
In the present work we considered the effect of $\mathrm{Nb}$ and charged vacancies in the properties of magnesium hydride. We performed spin polarized $\mathrm{ab}$ initio calculations substituting a $\mathrm{Mg}$ atom by a $\mathrm{Nb}$ impurity. Then some charged vacancies were included in the $\mathrm{MgH}_{2}+\mathrm{Nb}$ system $\left(\mathrm{V}_{\mathrm{H}}, \mathrm{V}_{\mathrm{Mg}}\right.$ or $\left.\mathrm{V}_{\mathrm{Mg}-\mathrm{H}}\right)$. In each case three possible charge states were considered $(+1,0$ or -1$)$. We computed cohesion and formation energy, bandgap and magnetic moment. We also calculate the transition level energy value and the density of states. $\mathrm{Nb}$ states are located in the gap, and a magnetic moment is induced. In the case of the system with charged vacancies we found that the $\mathrm{V}_{\mathrm{H}}{ }^{+}$and $\mathrm{V}_{\mathrm{H}}{ }^{0}$ are the more probable formed and the states near the Fermi level $\left(\mathrm{E}_{\mathrm{F}}\right)$ are filled thus getting an important reduction in the bandgap.
\end{abstract}




\section{Introduction}

It is well known that the replacement of fossil fuels is one of the most important topics against global warming. Hydrogen is the lightest element in the periodic table and has the highest gravimetric energy density of all known substances. Therefore, hydrogen is considered a strong candidate as a future energy carrier. ${ }^{1-5}$ The hydrogen's use as a fuel would be convenient, because the only combustion product is water, no other exhaust fumes, that might be possibly toxic or detrimental for the climate, are emitted. However, despite many years of research - except for a few pilot projects - hydrogen technology has still not been established as a broadly used technology in the renewable energy sector. During the last four decades the hydrogen storage in fuel cells and its subsequent reconversion to energy has been studied extensively. ${ }^{6-8}$ This is mainly because the requirements for an effective, safe and reliable way to store hydrogen is not yet met. Storage it as gas can be dangerous and the ratio volume/capacity of storage is the lowest; on the other hand, storing hydrogen as a liquid require temperatures around $20^{\circ} \mathrm{K}$ and it make it energetically expensive. ${ }^{9,10}$ One of the safest and most stable ways to store Hydrogen is in solid materials as absorbed specie. Many materials are being studied by the scientific community and metal hydrides are one of the most promising. ${ }^{11-15}$ Unfortunately, there are some problems when considered for practical applications, mainly due to the slowly kinetics in the hydrogenation/dehydrogenation processes and high dehydrogenation temperature. It has been found that kinetics and thermodynamics can be improved by reducing the size of the sample or adding defect-like vacancies or transition metals as impurities (TM: Nb, V, Ti, Zr). ${ }^{10,16-20}$ Particularly, magnesium hydride $\left(\mathrm{MgH}_{2}\right)$ has received special interest due to its low cost, availability, high gravimetric hydrogen capacity $(7.66 \mathrm{wt} \%)$ and lightweight. Besides energy storage, doped and undoped $\mathrm{MgH}_{2}$ can be useful in several technological areas like plasmonic color printing, thermos-solar applications, optoelectronic, switchable mirrors and spintronic. ${ }^{21-25}$ There are 
different works about the improvement of properties of $\mathrm{MgH}_{2}$. Chakrabarti et al., using Density Functional Theory (DFT), studied the effect of dehydrogenation efficiency on doping with rare earth elements in $\mathrm{MgH}_{2}$. The authors concluded that impurities can increase or decrease the hydrogen desorption energy. ${ }^{26}$ Salamani et al. established that the TM $(\mathrm{Nb}, \mathrm{V}$, $\mathrm{Cr}, \mathrm{Mn}, \mathrm{Co}, \mathrm{Ni}$ ) incorporation in the hydride, shows magnetic moments strongly localized. ${ }^{24}$ In our previous work, a similar behavior was observed in $\mathrm{MgH}_{2}$ containing vacancy with $\mathrm{q}$ charge state $\mathrm{V}_{\mathrm{X}} \mathrm{q}(\mathrm{X}: \mathrm{Mg}, \mathrm{H}, \mathrm{Mg}-\mathrm{H})$, founding localized magnetic moments $\mu=0.74 \mu_{\mathrm{B}}, 0.30$ $\mu_{\mathrm{B}}, 0.49 \mu_{\mathrm{B}}$ in $\mathrm{Mg}^{+}, \mathrm{Mg}^{0}$ and $\mathrm{Mg}-\mathrm{H}^{+}$vacancies, respectively. ${ }^{27}$

It has been observed that in $\mathrm{Nb}$-doped $\mathrm{MgH}_{2}$, the metal acts as a very effective catalyst favoring the $\mathrm{H}_{2}$ desorption and absorption. ${ }^{28-31}$ There are some interesting experimental studies in this system that allow us both to build a suitable theoretical model and to compare calculations with data. ${ }^{32,33}$ Nevertheless, there is not register about how magnetization works in this system and the effects of defects-like vacancies. Looking for improve the knowledge about $\mathrm{Nb}$-doped $\mathrm{MgH}_{2}$, we made DFT spin polarized ab initio calculations for the structure containing $\mathrm{H}$ vacancies $\left(\mathrm{V}_{\mathrm{H}}\right), \mathrm{Mg}$ vacancies $\left(\mathrm{V}_{\mathrm{Mg}}\right)$ or $\mathrm{Mg}-\mathrm{H}$ divacancies $\left(\mathrm{V}_{\mathrm{Mg}-\mathrm{H}}\right)$. For each vacancy type, calculation was performed with different charge states $q=+1,0$ and -1 .

\section{Computational Model}

To perform the calculations, it has been used the Vienna Ab-initio Simulation Package (VASP) code, within the frame of spin polarized DFT. The ion-core interaction was simulated by the projector augmented wave (PAW) pseudopotential and the PW91 functional was used as generalized gradient approximation (GGA) for the exchange-correlation term. ${ }^{34-}$ 37 The $\mathrm{MgH}_{2}$ has four polymorphs phases depending on the pressure and temperature. ${ }^{38}$ Among the them, $\alpha-\mathrm{MgH}_{2}$-represented in a rutile crystal structure ( $\mathrm{P} 42 / \mathrm{mnm}$, group No. 
136)- is the most stable phase at ambient pressure and room temperature. ${ }^{39}$ This structure was modeled using a supercell with 72 atoms ( $24 \mathrm{Mg}$ and $48 \mathrm{H}$ atoms). In order to perform the $\mathrm{Nb}$ doped $\mathrm{MgH}_{2}$ system, one $\mathrm{Mg}$ atom was replaced by a $\mathrm{Nb}$ atom, resulting a supercell with 23 $\mathrm{Mg}, 48 \mathrm{H}$ and one $\mathrm{Nb}$ atoms. The calculated lattice parameters were $\mathrm{a}=4.501 \AA, \mathrm{c} / \mathrm{a}=0.669$ and $\mathrm{x}=0.305 \AA$, which are in good agreement with those obtained both theoretically and experimentally. ${ }^{40,41}$ The vacancies sites were selected removing individual atoms from the supercell such that they were neighbors of $\mathrm{Nb}$ (see Figure 1). It was used a $4 \times 4 \times 4$ Monkhorst-Pack k-points mesh to sample the Brillouin zone and to perform the ionic relaxation. ${ }^{42}$ No constraints was used for the relaxation and it was implemented the conjugate gradient algorithm. The convergence criteria chosen for the convergence test was $10^{-4} \mathrm{eV} / \AA$ on each atom and a total energy of the down to $10^{-4} \mathrm{eV}$ between consecutives steps. For the density of electronic states, formation energies and magnetic moments were calculated, where a 15 x 15 x 15 k-points grid was employed. Finally, a cutoff of $650 \mathrm{eV}$ was selected for the plane-wave basis. The replacement of one $\mathrm{Mg}$ atom by a $\mathrm{Nb}$ atom as well as vacancies, plays an important role in dehydrogenation. The energetic cost of replacing a $\mathrm{Mg}$ atom with a $\mathrm{Nb}$ atom ( $\mathrm{E}_{\mathrm{coh}}$, called cohesion energy), is calculated using the following equation:

$$
\mathrm{E}_{\mathrm{coh}}(\text { doped })=\mathrm{E}_{\text {tot }}(\text { doped })+\mathrm{E}(\mathrm{Mg} \mathrm{HCP})-\left[\mathrm{E}(\mathrm{Nb} \mathrm{BCC})+\mathrm{E}\left(\mathrm{MgH}_{2}\right)\right]
$$

where the term $\mathrm{E}_{\text {tot }}\left(\right.$ doped) is the total energy of the doped supercell $\mathrm{MgH}_{2}+\mathrm{Nb}, \mathrm{E}\left(\mathrm{MgH}_{2}\right)$ is the total energy of the magnesium hydride bulk supercell and $\mathrm{E}(\mathrm{Nb})$ and $\mathrm{E}(\mathrm{Mg})$ are the energy of one atom of $\mathrm{Nb}$ and $\mathrm{Mg}$ in their respective bulk crystalline structure (BCC for $\mathrm{Nb}$, $\mathrm{HCP}$ for $\mathrm{Mg})$.

Regarding to charge defects, nowadays there is not a complete agreement about how to perform the calculations of their formation energy. ${ }^{43-46}$ Under this scenario and continuing the 
methodology of our previous work, the formation energy $E^{\text {form }}$ of a type $\mathrm{X}$ vacancy in the charge state q was calculated as

$$
E^{\text {form }}\left(X^{\mathrm{q}}\right)=E_{\text {tot }}\left(X^{\mathrm{q}}\right)-E_{\text {tot }}(\text { doped })+n_{i}\left(\mu_{i}+E_{\text {ref }, \mathrm{i}}\right)+q\left(E_{F}+E_{V}+V\right)
$$

where $E_{\text {tot }}\left(X^{q}\right)$ is the total energy of the supercell $\left(\mathrm{MgH}_{2}+\mathrm{Nb}\right)$ with defects of type $\mathrm{X}$ and charge state $\mathrm{q}$ and $\mathrm{n}_{\mathrm{i}}$ corresponds to the number of removed atoms of species $\mathrm{i}$ with chemical potential $\mu_{\mathrm{i} .}{ }^{27}$ For $\mathrm{H}$ and $\mathrm{Mg}$ species, the chemical potentials is referenced as follows: $\mathrm{E}_{\mathrm{ref}, \mathrm{H}}=1 / 2 \mathrm{E}\left(\mathrm{H}_{2}\right)$ and $\mathrm{E}_{\mathrm{ref}, \mathrm{Mg}}=\mathrm{E}(\mathrm{Mg})$, the energy per atom of $\mathrm{H}_{2}$ molecule and energy per atom of $\mathrm{Mg}$ bulk, respectively. In addition, the chemicals potentials are limited by the stability of the material by the relation $\mu_{\mathrm{Mg}}+\mu_{\mathrm{H}}=\Delta \mathrm{H}_{\mathrm{f}}\left(\mathrm{MgH}_{2}\right)$, where $\mu_{\mathrm{Mg}} \leq 0, \mu_{\mathrm{H}} \leq 0$ and $\Delta \mathrm{H}_{\mathrm{f}}\left(\mathrm{MgH}_{2}\right)$ is the formation enthalpy of the bulk $\mathrm{MgH}_{2}$. Considering that the more relevant conditions for $\mathrm{H}$ desorption are $\mathrm{H}$-poor concentration, it can be considered $\mu_{\mathrm{Mg}}=0$ and then $\mu_{\mathrm{H}}=1 / 2 \Delta \mathrm{H}_{\mathrm{f}}\left(\mathrm{MgH}_{2}\right)$. Finally, the Fermi level $\left(\mathrm{E}_{\mathrm{F}}\right)$ is referenced to the valence-band maximum $\left(\mathrm{E}_{\mathrm{V}}\right)$ of the doped material and the term $\Delta \mathrm{V}$ corrects $\mathrm{E}_{\mathrm{V}}$ due long-range nature of the electrostatic interactions between periodic images of the charged defects. Regarding the formation and the cohesion energy calculations, several authors support the applicability of this GGA method for defect systems due to fairly accurate total energies in large systems, of around 100 atoms, when two corrections are considered: Band-edge corrections due to the approximate DFT functional and Corrections due to the supercell approximation. ${ }^{47,48}$

It is well known that depending of Fermi level position one vacancy type can be stable in different charge states. In addition, if the Fermi level is raised to the nearest values to the conduction band (CB), the induced states by the defect within bandgap zone become filled with electrons. For this reason, is important to know the transition level energy value $\varepsilon\left(\mathrm{q} / \mathrm{q}^{\prime}\right)$, which indicates the defect levels corresponding to Fermi-level position where a charge state transition occurs; that is to say the Fermi-level position for which the formation energies of charge states $\mathrm{q}$ and $\mathrm{q}^{\prime}$ have the same value. The $\varepsilon\left(\mathrm{q} / \mathrm{q}^{\prime}\right)$ can be obtained from: 


$$
\varepsilon\left(\mathrm{q} / \mathrm{q}^{\prime}\right)=\left[\mathrm{E}_{\mathrm{f}}\left(\mathrm{D}_{\mathrm{q}} ; \mathrm{E}_{\mathrm{F}}=0\right)-\mathrm{E}_{\mathrm{f}}\left(\mathrm{D}_{\mathrm{q}^{\prime}} ; \mathrm{E}_{\mathrm{F}}=0\right)\right] /\left(\mathrm{q}^{\prime}-\mathrm{q}\right)
$$

where $E_{f}\left(D_{q} ; E_{F}=0\right)$ is the formation energy of the defect $D$ in the charge state $q$ when the Fermi level is at the valence band maximum $\left(\mathrm{E}_{\mathrm{F}}=0\right)$. The experimental interpretation of the transition level is that for Fermi-level positions below $\varepsilon\left(\mathrm{q} / \mathrm{q}^{\prime}\right)$ charge state $\mathrm{q}$ is stable, while for Fermi-level positions above $\varepsilon\left(\mathrm{q} / \mathrm{q}^{\prime}\right)$ charge state $\mathrm{q}^{\prime}$ is stable.

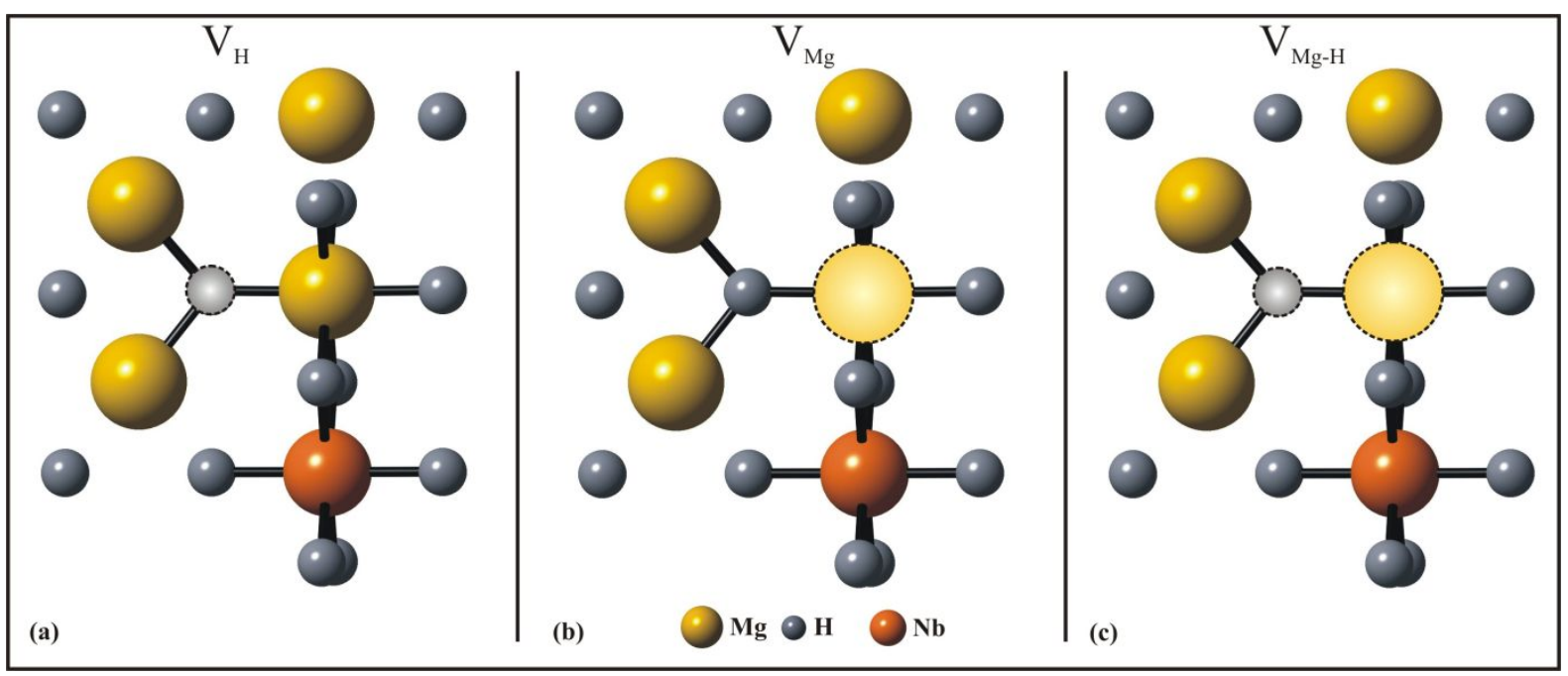

Figure 1: $\mathrm{H}$ vacancy (a), $\mathrm{Mg}$ vacancy (b) and complex $\mathrm{Mg}-\mathrm{H}$ divacancy (c) site in $\mathrm{Nb}$ doped $\mathrm{MgH}_{2}$ (For the sake of clarity, only the sites around the impurity is shown).

\section{Results and Discussion}

\section{1 $\mathrm{Nb}$ doped $\mathrm{MgH}_{2}$}

From equation (1) we computed the energy needed to substitute one $\mathrm{Nb}$ at a $\mathrm{Mg}$ site. It is $1.88 \mathrm{eV}$, similar to values reported by Kumar et al. ${ }^{49}$ It can be seen in Figure 2 that a substitutional $\mathrm{Nb}$ atom located at a $\mathrm{Mg}$ atom position produces a small local non-symmetrical distortion in the structure, where the most affected atoms are the near neighbors to $\mathrm{Nb}$ atom. This geometric rearrangement is a consequence of charge redistribution and different atomic sizes. The modified closest $\mathrm{Mg}-\mathrm{Mg}$ and $\mathrm{Mg}-\mathrm{H}$ distances are $3.55 \AA$ and $1.96 \AA$, respectively. While in the pure $\mathrm{MgH}_{2}$ are $3.52 \AA$ and $1.94 \AA$, respectively. The $\mathrm{Nb}-\mathrm{Mg}$ and $\mathrm{Nb}-\mathrm{H}$ bond 
length are found to be $3.03 \AA$ and $1.95 \AA$, respectively. The elongation of $\mathrm{Mg}-\mathrm{H}$ bond lengths is suggestive of an easier dissociation and consequently reduced hydrogen adsorption energy. These results are in good agreement with those reported by Hussain et al. ${ }^{50}$

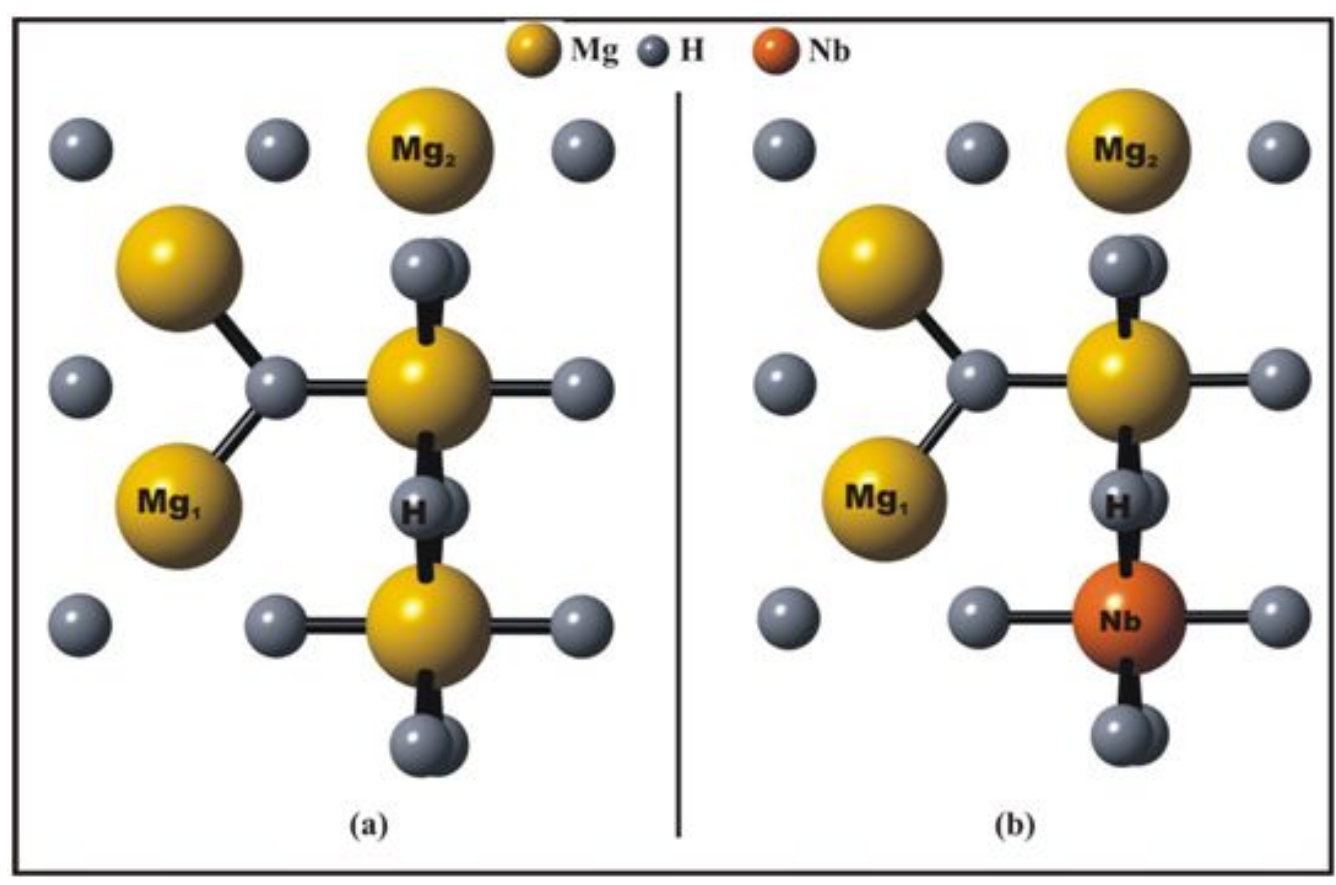

Figure 2: Local structure around of impurity site. Before (a) and after (b) the $\mathrm{Nb}$ substitutional impurity incorporation.

Regarding electronic structure, Figure 3 shows total and partial DOS curves for the hydride before and after the $\mathrm{Nb}$ impurity incorporation. Figures 3(a) and (b) show hybridization of $\mathrm{Mg}$ and $\mathrm{H}$ atoms, which is a signal of strong ionic $\mathrm{Mg}-\mathrm{H}$ bonds. The valence band (VB) and $\mathrm{CB}$ are separated by an energy gap of $3.79 \mathrm{eV}$. This value is smaller than those experimentally obtained $(5.6 \pm 0.1 \mathrm{eV}) .{ }^{51}$ It is well known that for several semiconductors and insulators, this discrepancy can be attributed to the Kohn-Sham formalism implemented in DFT resulting in underestimation of band gaps values. ${ }^{52}$ But we are only interested in a qualitative comparison. When the $\mathrm{Nb}$ impurity is introduced the DOS curves are shifted to lower energies and new states appearing in the gap (see Figure 3(c)). These new states are mainly formed by the d orbitals of the impurity with a small contribution of $\mathrm{Mg}$ and $\mathrm{H}$ 
orbitals (compare Figure 3(b) with (d)). Because of this, an important reduction in the bandgap is found. Hussain et al reported similar behavior in $\mathrm{Nb}$ doped $\alpha-\beta$ - and $\gamma-\mathrm{MgH}_{2}$ phases $^{50,53}$. Also, it can be seen that spin up and spin down DOS contributions are asymmetric, which is consistent with an induced magnetic moment of $2.11 \mu_{\mathrm{B}}$. This induced magnetism is coming mainly from the impurity, with a slightly polarization on the nearest neighbors. These results are similar as those reported by Lu et al. by defective $\mathrm{MgH}_{2}$ (with substitutional TM, TM $=\mathrm{V}, \mathrm{Cr}, \mathrm{Mn}, \mathrm{Fe}, \mathrm{Co}$ or $\mathrm{Ni}) .{ }^{54}$

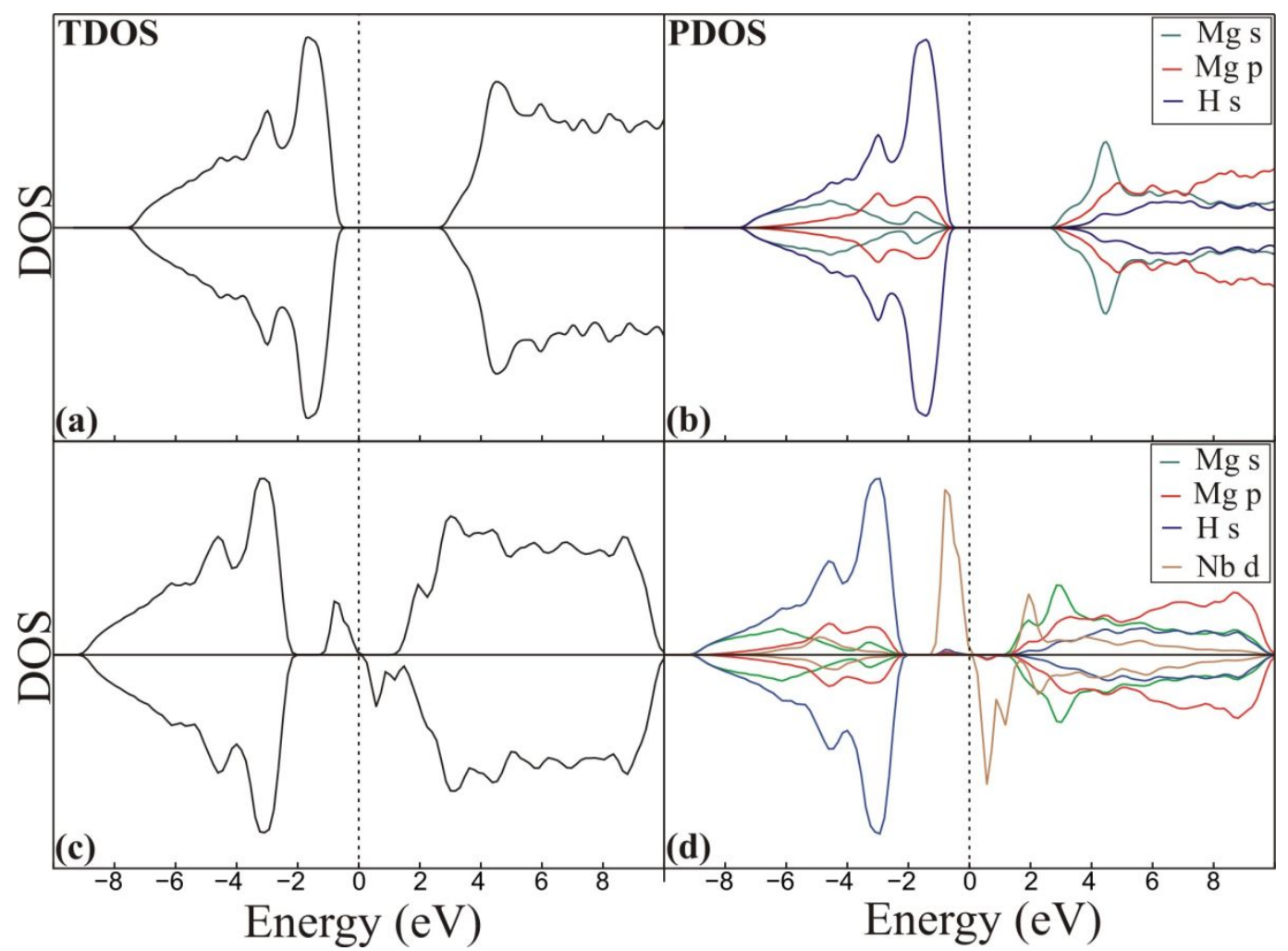

Figure 3: Total and partial DOS curves before (a) and (b); and after the Nb substitutional impurity incorporation (c) and (d).

Currently these hydride types are also studied as potential candidates for the so-called "hydride electronics". Using an analogy with the transparent conducting oxides (TCOs), the hydride can be classified in type-s or type-d, depending on dominant contribution of the s- or d-electrons on the top-most $\mathrm{VB}$ and bottom-most $\mathrm{CB} .{ }^{55}$ For this reason, is important to 
analyze the DOS curves behavior in the valence and conduction bands. In the undoped case, the Fermi level is closer to the VB, indicating a p-type semiconductor. Total DOS curves show that the top-most VB and bottom-most $\mathrm{CB}$ are well dispersed. It can be seen from the PDOS curves that both top-most VB and bottom-most CB manly contributions are from $\mathrm{s}$ orbitals. The top-most VB is mostly composed by $\mathrm{H}$ atom s orbitals whereas in the bottommost $\mathrm{CB}$ the $\mathrm{s}$ orbitals come from $\mathrm{Mg}$ atoms. This behavior is similar to well-known semiconductors used for electronics devices (for example Si and GaAs), which suggest that this hydride could present electrical current transport with the right dopant. Experimental results show that the magnesium hydrides with the right transition metals impurity exhibits a semiconducting transparent behavior. But these are preliminary result a still far from meeting the goals for practical applications. ${ }^{56}$ In the hydride-impurity system we can see that the bandgap is reduced and the conduction is improved. Also, the DOS curves show a shift in the Fermi level to the $\mathrm{CB}$, which change the system to a n-type semiconductor. The introduction of deep localized states that divide the gap in two smaller parts, makes the introduction of defects an important tool for the modulation of optical properties, and also could be utilized for bandgap engineering and insulator-semiconductor transitions. In this system the gap is divided in two bands, but the second bandgap (i. e. the energy difference between the nearest two bottom-most $\mathrm{CBs}$ ) is $<3.1 \mathrm{eV}$ that is an indication of loss of transparency.

\subsection{Charged Vacancies in $\mathrm{MgH}_{2}$ and $\mathrm{Nb}$ doped $\mathrm{MgH}_{2}$}

Figure 4 summarizes the transition level energy within the band gap (a-c) and the formation energy as a Fermi level function (d) for positive, neutral and negative vacancies in $\mathrm{Nb}$ doped $\mathrm{MgH}_{2}$. Table 1 and Figures 4(a-c) show the values and position within the bandgap of transition level $\varepsilon\left(\mathrm{q} / \mathrm{q}^{\prime}\right)$ for each studied vacancy species. In all cases it can be noted that the donor level $\varepsilon(+/ 0)$ has a value lower than the acceptor level $\varepsilon(0 /-)$, this fact reflects a positive repulsion energy $\mathrm{U} .{ }^{57}$ That is to says, the three charge states,+ 0 , - can be thermodynamically 
stable depending upon the position of the Fermi level. The U corresponds to the difference between the donor and acceptor levels. For $\mathrm{V}_{\mathrm{H}}, \mathrm{V}_{\mathrm{Mg}}$ and $\mathrm{V}_{\mathrm{Mg}-\mathrm{H}}$ the $\mathrm{U}$ value is $0.8 \mathrm{eV}, 0.3 \mathrm{eV}$ and $0.2 \mathrm{eV}$, respectively.

In addition, from Figure $4(\mathrm{~d})$ it can be noted that the hydrogen vacancy $\left(\mathrm{V}_{\mathrm{H}}\right)$ is the lowest energy defect, whereas the magnesium vacancy $\left(\mathrm{V}_{\mathrm{Mg}}\right)$ has the highest formation energy. Also, the formation energy of $\mathrm{V}_{\mathrm{Mg}-\mathrm{H}}$ complex is higher than $\mathrm{V}_{\mathrm{H}}$ and lower than $\mathrm{V}_{\mathrm{Mg}}$. Then, the hydrogen vacancy is dominant defect respect to other vacancy types. Furthermore, the positive hydrogen vacancy is the most likely to be formed in the $\mathrm{Nb}$ doped $\mathrm{MgH}_{2}$ system, presumably attributed to the $\mathrm{Nb}$ effects in the hydride. The $\mathrm{Nb}$ presences improves the hydrogen desorption, and the $\mathrm{V}_{\mathrm{H}}{ }^{+}$diffuse more readily than $\mathrm{V}_{\mathrm{H}}{ }^{0}$. This behavior could be attributed to the ionic nature of $\mathrm{MgH}_{2}$.

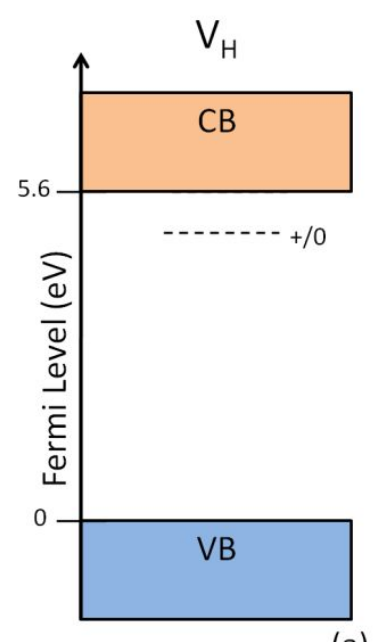

(a)

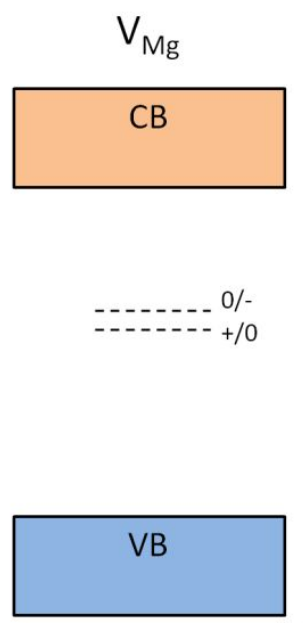

(b)

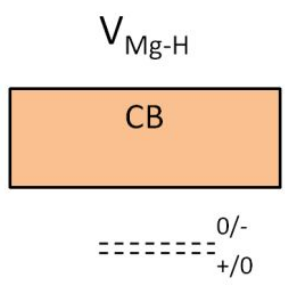

VB

(c) 


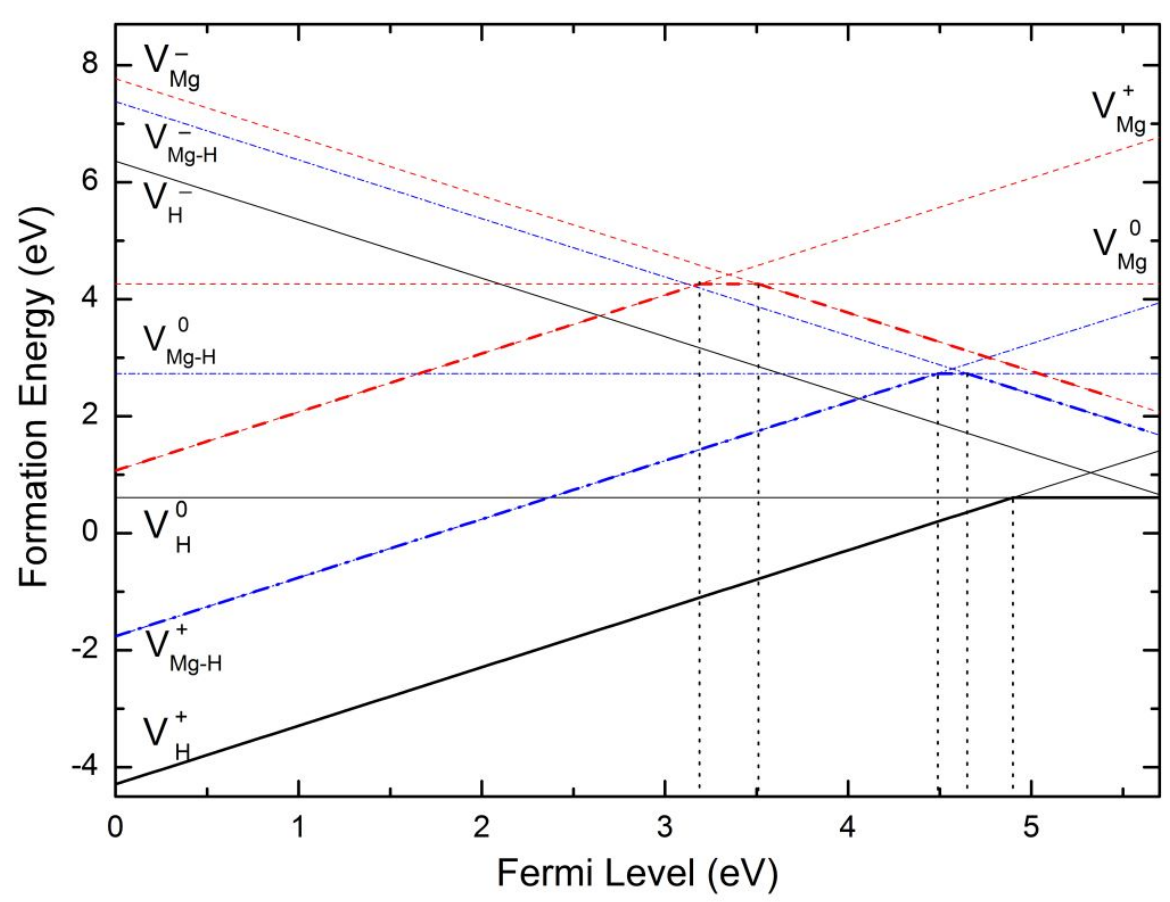

(d)

Figure 4: Schematic diagram of transition level energy for (a) Hydrogen vacancy $\left(\mathrm{V}_{\mathrm{H}}\right),(\mathrm{b})$ magnesium vacancy $\left(\mathrm{V}_{\mathrm{Mg}}\right)$ and (c) hydrogen-magnesium vacancy complex $\left(\mathrm{V}_{\mathrm{Mg}-\mathrm{H}}\right)$ in $\mathrm{Nb}$ doped $\mathrm{MgH}_{2}$. Defect formation energies $\left(\mathrm{E}_{\text {form }}\right)$ as a function of Fermi energy $\left(\mathrm{E}_{\mathrm{F}}\right)$ for $\mathrm{Nb}$ doped $\mathrm{MgH}_{2}$ containing native defects, each one in their different charge state (d). The black dotted lines indicate the energy transition level $\varepsilon\left(\mathrm{q} / \mathrm{q}^{\prime}\right)$.

Table 1. Energy transition level $\varepsilon\left(\mathrm{q} / \mathrm{q}^{\prime}\right)$ and $U$ energy for hydrogen, magnesium and hydrogen-magnesium vacancy in $\mathrm{Nb}$ doped $\mathrm{MgH}_{2}$. All units are in $\mathrm{eV}$.

\begin{tabular}{lccc}
\hline Vacancy & $\varepsilon(+/ 0)$ & $\varepsilon(0 /-)$ & $\mathrm{U}$ \\
\hline $\mathrm{V}_{\mathrm{H}}$ & 4.9 & 5.7 & 0.8 \\
$\mathrm{~V}_{\mathrm{Mg}}$ & 3.2 & 3.5 & 0.3 \\
$\mathrm{~V}_{\mathrm{Mg}-\mathrm{H}}$ & 4.5 & 4.7 & 0.2 \\
\hline
\end{tabular}


Considering that the formation energy plot (see Figure 4(d)) shows that the H vacancy with positive and neutral charge are the most probable formed defects, in the following we only analyze these two cases.

Figure 5 shows the local structural changes induced by vacancy incorporation in $\mathrm{MgH}_{2}+\mathrm{Nb}$ system, where the contracted bonds are red, while elongated ones are green. It can be seen that in the cases of neutral and positive $H$ vacancies, local non-symmetrical distortion in the structure is produced. The most affected atoms are the near $\mathrm{Nb}$ neighbors, as a consequence of charge redistribution. The $\mathrm{Mg}$ atoms first neighbors to the vacancy are moved away, from $1.96 \AA$ to $2.01 \AA$ and $1.99 \AA$ for neutral and positive $\mathrm{H}$ vacancy, respectively. For the neutral vacancy the $\mathrm{Mg}-\mathrm{Mg}$ bond distance for the atoms nearest to vacancy and the $\mathrm{Nb}$ atom is contracted about $2 \%(5 \%)$ respect to the system with $\mathrm{Nb}$ for the neutral (positive) $\mathrm{H}$ vacancy, while the $\mathrm{Mg}-\mathrm{Mg}$ bond for the atoms nearest to the vacancy is elongated approximately $5 \%$ and $3 \%$ for neutral and positive $H$ vacancy, respectively. In the case of a neutral vacancy, the $\mathrm{Mg}-\mathrm{H}$ distances remains unaffected except for those with the $\mathrm{H}$ atoms nearest to the $\mathrm{Nb}$ that are elongated from $1.96 \AA$ to $2.00 \AA$, while all $\mathrm{Mg}-\mathrm{H}$ bonds are elongated about $0.07 \AA$ for the case of positive vacancy. The $\mathrm{Nb}-\mathrm{Mg}$ bond length is found to be $2.88 \AA$ and $2.85 \AA$, for neutral and positive $\mathrm{H}$ vacancy respectively. For $\mathrm{Nb}-\mathrm{H}$ bonds it can be seen that four of them contracted from $1.95 \AA$ to $1.91 \AA$, while the other two are elongated from $1.95 \AA$ to $1.98 \AA$ for $\mathrm{H}$ neutral vacancy. In the case of a positive $\mathrm{H}$ vacancy, the behavior is the same, with four bonds contracted from $1.95 \AA$ to $1.88 \AA$ and two elongated from $1.95 \AA$ to $1.98 \AA$. 


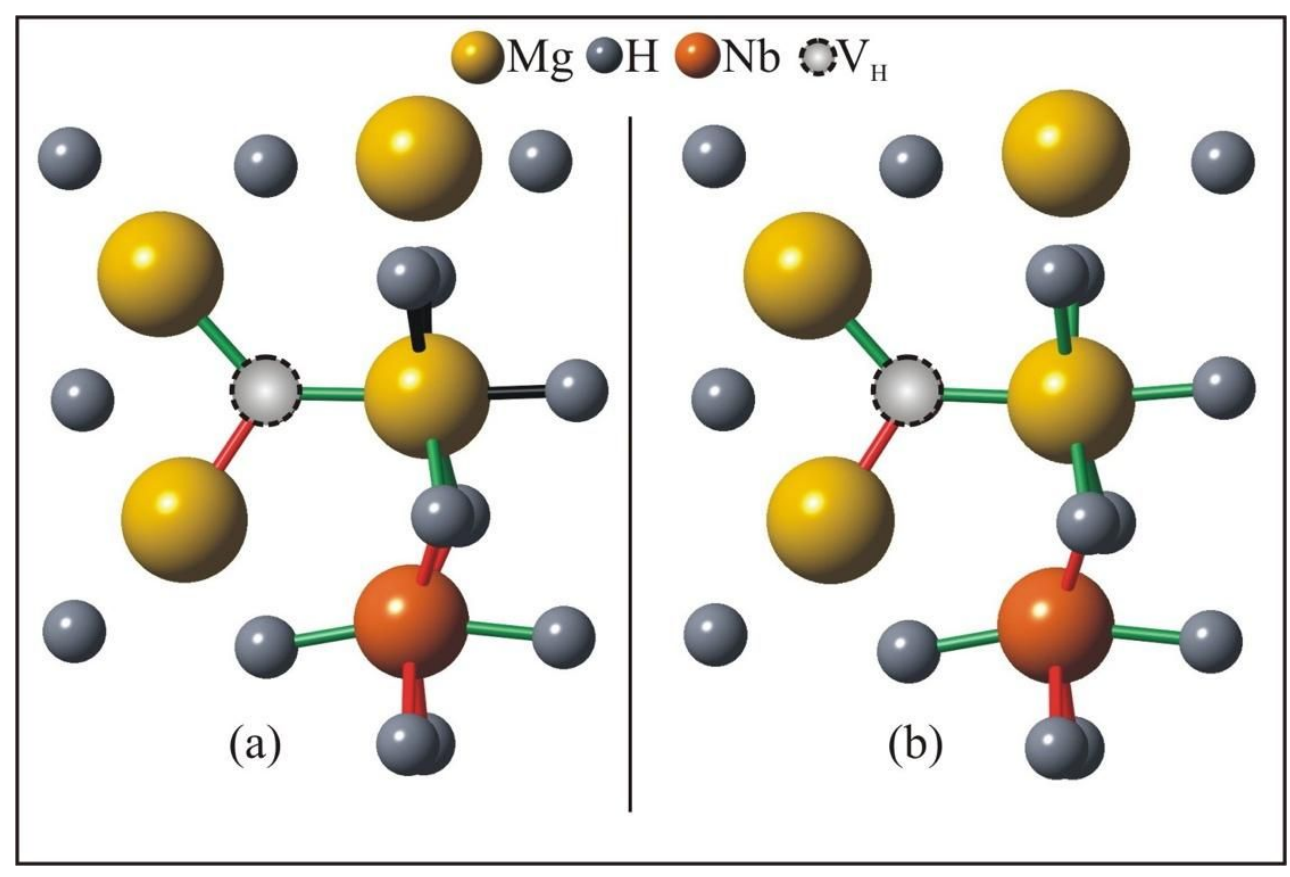

Figure 5: Local structure around of impurity site for the system $\mathrm{MgH}_{2}+\mathrm{Nb}$. With neutral (a) and positive (b) H vacancy. In this Figure the bonds in red are contracted, while the green ones are elongated with respect to those in the system $\mathrm{MgH}_{2}+\mathrm{Nb}$.

Regarding the electronic structure, Figure 6 shows total and partial DOS curves for the hydride with $\mathrm{Nb}$ impurity, for neutral and positive $\mathrm{H}$ vacancy. It can be seen from this figure that the Nb-d states are splitting around the Fermi level for both cases. In addition, the hybridized states at the Fermi level produce an important reduction in the bandgap for the neutral $\mathrm{H}$ vacancy, while in the case of positive $\mathrm{H}$ vacancy almost not bandgap is founded. These results show an improvement in the conduction, but also make this system not transparent. Also, a small shift to higher energies is showed for the DOS curves of positive $\mathrm{H}$ vacancy (compared figure 3(c) with figure 6(c)). As before the DOS curves are not symmetrical, which is consistent with a non-zero induced magnetic moment. The induced magnetic moment is $1.49 \mu_{\mathrm{B}}$ and $1.36 \mu_{\mathrm{B}}$ for neutral and positive $\mathrm{H}$ vacancy, respectively. This reduction is a consequence of the polarization of the near neighbors. 


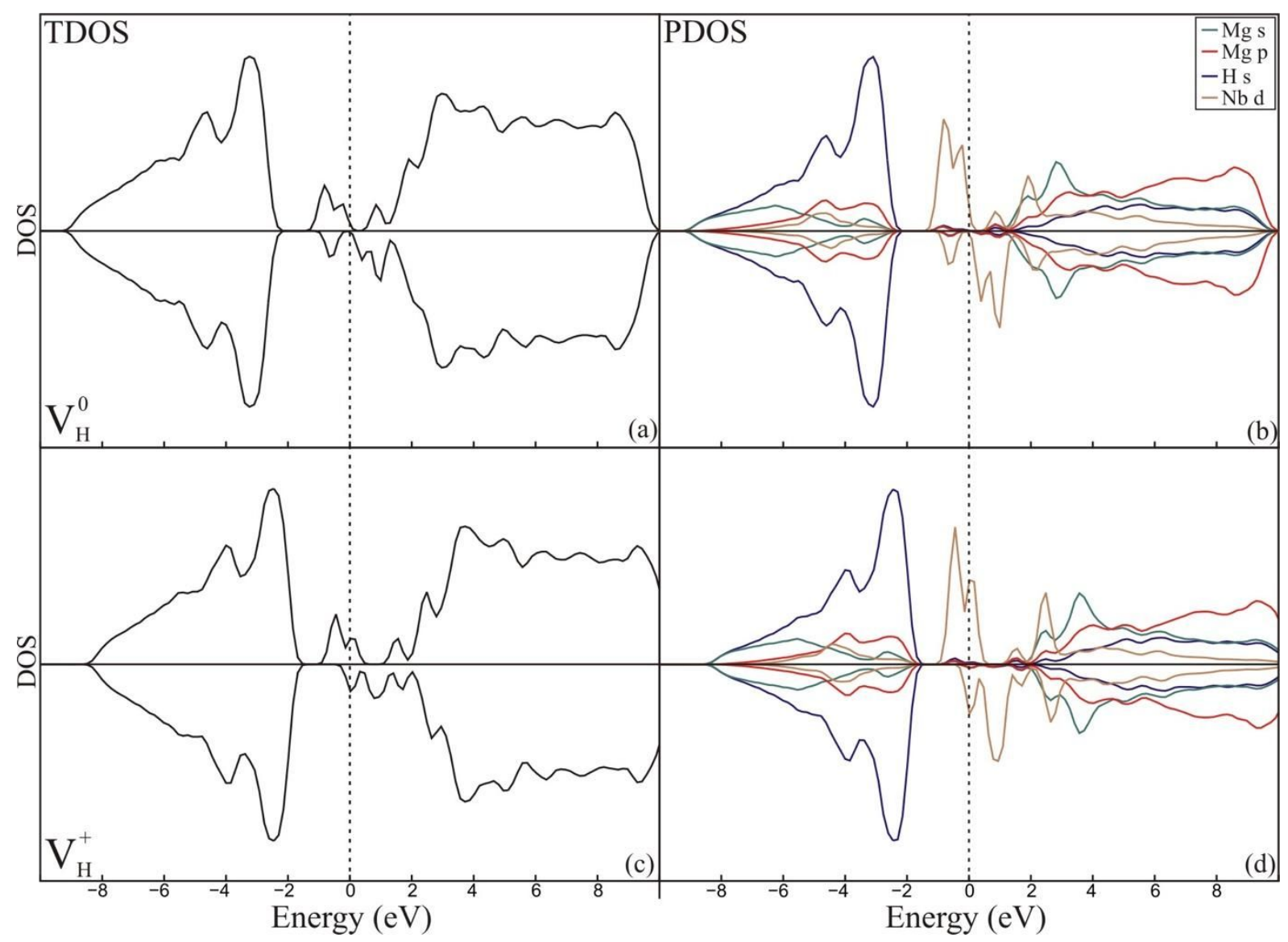

Figure 6: Total and partial DOS curves for $\mathrm{MgH}_{2}+\mathrm{Nb}$ system with neutral (a) and (b); and positive (c) and (d) H vacancy.

For a better understanding of the atom interactions, the PDOS by atom is analyzed. It can be seen that in the case of system $\mathrm{MgH}_{2}+\mathrm{Nb}$, the $\mathrm{Nb}$ atom mostly interacts with the $\mathrm{Mg}$ atom (see Figure 7(a-d)). The induced magnetic moment comes mostly from the $\mathrm{Nb}$ d orbitals (see Figure $7(d)$ ). When the charged vacancy is introduced, the states in the Fermi level are splitted. In both cases the $\mathrm{Nb}$ atom major interactions are with the $\mathrm{Mg}$ atoms. But unlike the system without vacancy, the $\mathrm{Nb}-\mathrm{H}$ interaction is noticeable in the DOS curves (compare Figure $7(\mathrm{c})$ with Figure $7(\mathrm{~g})$ and $7(\mathrm{k}))$. In all cases the most important changes are located at $\mathrm{CB}$, which is consistent with the fact that the $\mathrm{Nb}$ is a donor. It can be seen in this figure that the reduction in the induced magnetic moment comes from an important polarization of the $\mathrm{Mg}$ and $\mathrm{H}$ near neighbors. 


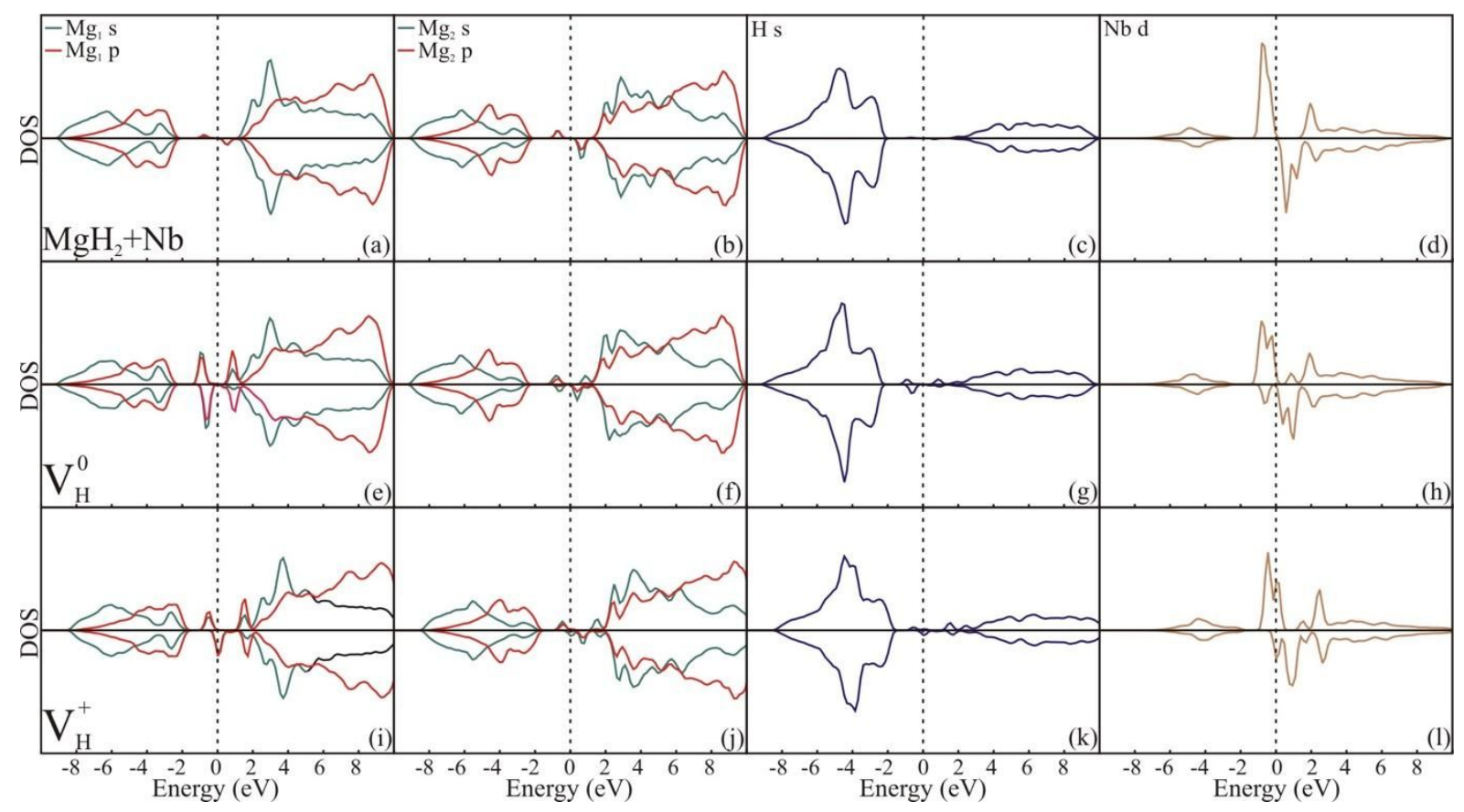

Figure 7: DOS curves for $\mathrm{MgH}_{2}+\mathrm{Nb}$ system projected on $\mathrm{Mg}_{1}$ atom (a), $\mathrm{Mg}_{2}$ atom (b), $\mathrm{H}$ atom (c) and $\mathrm{Nb}(\mathrm{d})$. DOS curves for $\mathrm{MgH}_{2}+\mathrm{Nb}$ system - with neutral $\mathrm{H}$ vacancy - projected on $\mathrm{Mg}_{1}$ atom (a), $\mathrm{Mg}_{2}$ atom (b), $\mathrm{H}$ atom (c) and $\mathrm{Nb}(\mathrm{d})$. DOS curves for $\mathrm{MgH}_{2}+\mathrm{Nb}$ system with positive $\mathrm{H}$ vacancy - projected on $\mathrm{Mg}_{1}$ atom (a), $\mathrm{Mg}_{2}$ atom (b), $\mathrm{H}$ atom (c) and $\mathrm{Nb}(\mathrm{d})$.

\section{Conclusion}

In the present work, it has been studied $\mathrm{Nb}$ doped $\mathrm{MgH}_{2}$ with and without vacancies like defects. $\mathrm{H}$ vacancy, $\mathrm{Mg}$ vacancy and $\mathrm{H}-\mathrm{Mg}$ di-vacancy (idem) in different charge states were analyzed using spin polarized DFT calculations. The most relevant conclusions for $\mathrm{Nb}$ doped $\mathrm{MgH}_{2}$ bulk can be summarized as follow:

- The incorporation of $\mathrm{Nb}$ induces a magnetic moment of $2.11 \mu_{\mathrm{B}}$ in the $\mathrm{MgH}_{2}$ (nonmagnetic material), acting as a donor for spin down and as acceptor for spin up.

- $\mathrm{Nb}$ presence introduces a small change in the $\mathrm{Mg}-\mathrm{H}$ distances, and only affects their first neighbors, from $1.94 \AA$ to $1.96 \AA$, signal of a slight enhancement in the $\mathrm{H}$ desorption. 
- Tramp states appear, producing an important reduction in the bandgap. Also, a shift towards lower energies is observed in DOS curves.

- It could have optoelectronics applications due to its high bandgap and the welldispersed top-most VB and bottom-most $\mathrm{CB}$. With transition metals impurities the hydride exhibits a conversion from the metallic reflective state to the semiconducting transparent state. In the case of $\mathrm{Nb}$ the conduction increases but the transparence is highly reduced.

Regarding to $\mathrm{Nb}$ doped system containing charged vacancies, it can be concluded the following:

- The $\mathrm{V}_{\mathrm{H}}^{+}$and $\mathrm{V}_{\mathrm{H}}{ }^{0}$ are the most probable vacancies to be formed, due to their lowest formation energy.

- For the case of $\mathrm{V}_{\mathrm{H}}{ }^{0}$, the $\mathrm{Mg}-\mathrm{H}$ distances remains unaffected except for those with the $\mathrm{H}$ atoms nearest to the $\mathrm{Nb}$ which change from $1.96 \AA$ to $2.00 \AA$, while all $\mathrm{Mg}-\mathrm{H}$ bonds are elongated about $0.07 \AA$ for the runs with $\mathrm{V}_{\mathrm{H}}^{+}$.

- Four of the six Nb-H bonds are contracted from $1.95 \AA$ to $1.91 \AA$ while the other two are elongated from $1.95 \AA$ to $1.98 \AA$ for $\mathrm{H}$ neutral vacancy. For $\mathrm{H}$ positive vacancy, the elongated ones have the same behavior and the four contracted bonds change from $1.95 \AA$ to $1.88 \AA$.

- Both $\mathrm{V}_{\mathrm{H}}^{+}$and $\mathrm{V}_{\mathrm{H}}^{0}$ produce a reduction in the bandgap, showing an improvement in the conduction, but also make this system not transparent.

- Compared to the $\mathrm{Nb}$ doped $\mathrm{MgH}_{2}$ system without vacancies, the $\mathrm{V}_{\mathrm{H}}{ }^{+}$and $\mathrm{V}_{\mathrm{H}}{ }^{0}$ reduce the bandgap and induce a lower magnetic moment, $1.49 \mu_{\mathrm{B}}$ with $\mathrm{V}_{\mathrm{H}}{ }^{0}$ and $1.36 \mu_{\mathrm{B}}$ with $\mathrm{V}_{\mathrm{H}}{ }^{+}$. Therefore, doped material could have a hypothetical use in spintronics due to the different behavior between spin up DOS curve and spin down one. 
Summarizing for the $\mathrm{MgH}_{2}$ we found that due to its high bandgap energy is potentially an interesting candidate for switchable smart mirror applications. In the case of doped magnesium hydride, the impurity states are in the gap and these add a magnetic characteristic to a semiconductor. We found a different bandgap in both spin directions. Also, a different spin up and spin down contribution to DOS leading the system to a spin polarized features that could be used in magnetic tunnel junctions. In addition, using a spin filter of materials with these two characteristics could provide different spin polarized currents of interest in spintronics devices. Considering this system for optoelectronics applications is clear that $\mathrm{Nb}$ generates a loss in transparency. On the other hand, with the present of vacancies $\left(\mathrm{V}_{\mathrm{H}}{ }^{0}\right.$ and $\mathrm{V}_{\mathrm{H}}{ }^{+}$) the system shows an important increase in the number of states in the gap crossing the Fermi level and the material becomes almost conductor while keeping its magnetism. Also, the system losses all possibility of TCOs behavior. Thus, controlling the vacancies concentration is important when the transparency and semiconductor behavior are needed.

From the point of view of hydrogen storage, $\mathrm{Nb}$ and vacancies elongate the metal- $\mathrm{H}$ bonds making hydrogen desorption easer.

\section{Acknowledgments}

Our work was supported by ANPCyT through PICT 2016 Raíces N ${ }^{\circ}$ 2016-4085 Res. N ${ }^{\circ}$ 285/16 and PICT 2016 N²016-4094 Res. N²85/16 research grants, as well as by SGCyTUNS. CRL, EG and PVJ are members of CONICET. FG and VO are fellow researcher at this institution. RF wish to thank the Uruguayan funding institutions CSIC, ANII and PEDECIBA.

\section{References}


(1) Vajo, J. J.; Mertens, F.; Ahn, C. C.; Bowman, R. C.; Fultz, B. Altering hydrogen storage properties by hydride destabilization through alloy Formation: $\mathrm{LiH}$ and $\mathrm{MgH}_{2}$ destabilized with Si. J. Phys. Chem. B 108, 2004, 13977-13983.

(2) David, W. I. F. Effective hydrogen storage: a strategic chemistry challenge. Faraday Discuss. 151, 2011, 399-414.

(3) Ley, M. B.; Jepsen, L. H.; Lee, Y.-S.; Cho, Y. W.; Bellosta von Colbe, J. M.; Dornheim, M.; Rokni, M.; Jensen, J. O.; Sloth, M.; Filinchuk, Y. et. al. Complex hydrides for hydrogen storage - new perspectives. Mater. Today 17, 2014, 122-128.

(4) Møller, T. K.; Sheppard, D.; Ravnsbæk, B. D.; Buckley, E. C.; Akiba, E.; Li, H.-W.; Jensen, R. T. Complex metal hydrides for hydrogen, thermal and electrochemical energy storage. Energies 10, 2017, 1645.

(5) Møller, K. T.; Jensen, T. R.; Akiba, E.; Li, H.-W. Hydrogen - a sustainable energy Carrier Prog. Nat. Sci. Mat. Int. 27, 2017, 34-40.

(6) Selvam, P.; Viswanathan, B.; Swamy, C. S.; and V. Srinivasan, C. S. Magnesium and magnesium alloys hydrides. Int. J. Hydrogen Energy 11, 1986, 169-192.

(7) Zhou, H.; Liu, H. -Z.; Xu, L.; Gao, S. -C.; Wang, X. -H.; Yan, M. Hydrogen storage properties of Nb-compounds-catalyzed $\mathrm{LiBH}_{4}-\mathrm{MgH}_{2}$. Rare Met. 36, 2017, 723-728.

(8) Jepsen, J.; Milanese, C.; Puszkiel, J.; Girella, A.; Schiavo, B.; Lozano, G. A.; Capurso, G.; Bellosta von Colbe, J. M.; Marini, A.; Kabelac, S.; Dornheim, M.; Klassen, T. Fundamental material properties of the $2 \mathrm{LiBH}_{4}-\mathrm{Mg}_{2}$ reactive hydride composite for hydrogen Storage: (II) Kinetic properties. Energies 2018, 11, 1170.

(9) Sakintunaa, B.; Lamari-Darkrimb, F.; Hirscher, M. Metal hydride materials for solid hydrogen storage: A review. Int. J. Hydrogen Energy 2007, 32, 1121-1140. 
(10) Sadhasivam, T.; Kim, H.-T.; Jung, S.; Roh, S.-H.; Park, J.-H.; Jung, H.-Y. Dimensional effects of nanostructured $\mathrm{Mg} / \mathrm{MgH}_{2}$ for Hydrogen storage applications: A review. Renewable Sustainable Energy Rev. 2017, 72, 523-534.

(11) Li, F.; Bashir, S.; Liu, J. L. Nanostructured Materials for Next-Generation Energy Storage and Conversion: Fuel Cells; Springer: Berlin, 2018.

(12) Callini, E.; Aguey-Zinsou, K.-F.; Ahuja, R.; Ares, J. R.; Bals, S.; Biliškov, N.; Chakraborty, S.; Charalambopoulou, G.; Chaudhary, A.-L.; Cuevas, F. et al. Nanostructured materials for solid-state hydrogen storage: A review of the achievement of COST Action MP1103. Int. J. Hydrogen Energy 2016, 41, 14404-14428.

(13) Yahya, M. S.; Ismail, M. Improvement of Hydrogen Storage Properties of $\mathrm{MgH}_{2}$ Catalyzed by $\mathrm{K}_{2} \mathrm{NbF}_{7}$ and Multiwall Carbon Nanotube. J. Phys. Chem. C. 2018, 122, $11222-11233$.

(14) Cheng, C.; Chen, M.; Xiao, X.; Huang, X.; Zheng, J.; Chen, L. Superior Reversible Hydrogen Storage Properties and Mechanism of $\mathrm{LiBH}_{4}-\mathrm{MgH}_{2}-\mathrm{Al}$ Doped with $\mathrm{NbF}_{5}$ Additive. J. Phys. Chem. C 2018, 122, 7613-7620.

(15) Pandey, S. K.; Bhatnagar, A.; Mishra, S. S.; Yadav, T. P.; Shaz, M. A; Srivastava, O. N. Curious Catalytic Characteristics of Al-Cu-Fe Quasicrystal for De/Rehydrogenation of $\mathrm{MgH}_{2}$. J. Phys. Chem. C 2017, 121, 24936-24944.

(16) Jain, I.P.; Lal, C.; Jain, A. Hydrogen storage in Mg: a most promising material. Int. J. Hydrogen Energy 2010, 35, 5133-5144.

(17) Pourabdoli, M.; Raygan, S.; Abdizadeh, H.; Uner, D. Determination of kinetic parameters and hydrogen desorption characteristics of $\mathrm{MgH}_{2}-10$ wt\% (9Ni-2Mg-Y) nanocomposite. Int. J. Hydrogen Energy 2013, 38, 11910-11919.

(18) Sun, G.; Li, Y.; Zhao, X.; Wu, J.; Wang, L.; Mi, Y. First-principles investigation of effects of $\mathrm{Ni}$ and co-doped on destabilized $\mathrm{MgH}_{2}$. $R S C A d v$. 2016, 6, 23110-23116. 
(19) Li, G.; Blake, G. R.; Palstra, T. T. M. Vacancies in functional materials for clean energy storage and harvesting: the perfect imperfection. Chem. Soc. Rev. 2017, 46, 1693-1706.

(20) Song, Y.; Guo, Z. X.; Yang, R. Influence of Selected Alloying Elements on the Stability of Magnesium Dihydride for Hydrogen Storage Applications: A First-Principles Investigation. Phys. Rev. B: Condens. Matter Mater. Phys. 2004, 69, 94205.

(21) Duan, X.; Kamin, S.; Liu, N. Dynamic plasmonic colour display. Nat. Commun. 2017, 8, 14606.

(22) Kumar, S.; Kojima, Y.; Kain, V. Nano-engineered $\mathrm{Mg}-\mathrm{MgH}_{2}$ system for solar thermal energy storage. Sol. Energy 2017, 150, 532-537.

(23) Kerssemakers, J. W. J.; Van der Molen, S. J.; Koeman, N. J.; Günther, R.; Griessen, R. Pixel switching of epitaxial $\mathrm{Pd} / \mathrm{YH}_{\mathrm{X}} / \mathrm{CaF}_{2}$ switchable mirrors. Nature 2010, 406, 489-491.

(24) Salmani, E.; Laghrissi, A.; Laamouri, R.; Benchafia, E.; Ez-Zahraouy, H.; Benyoussef, A. Monte Carlo and Ab-initio calculation of TM (Ti, V, Cr, Mn, Fe, Co, Ni) doped $\mathrm{MgH}_{2}$ hydride: GGA and SIC approximation. J. Magn. Magn. Mater. 2017, 424, 53-63.

(25) Nayak, V.; Verma, U. P. Phase transition and optoelectronic properties of $\mathrm{MgH}_{2}$. Phase Transitions 2015, 89, 437-447.

(26) Chakrabarti, S.; Biswas, K. Effect on de-hydrogenation efficiency on doping of rare earth elements (Pr, Nd, Gd, Dy) in $\mathrm{MgH}_{2}-\mathrm{A}$ density functional theory study. Int. J. Hydrogen Energy 2016, 42, 1012-1017.

(27) Gaztañaga, F.; Luna, C. R.; Sandoval, M.; Macchi, C.; Jasen, P. Geometric, Electronic and Magnetic Properties of $\mathrm{MgH}_{2}$ : Influence of Charged Defects. J. Phys. Chem. C 2016, $120,22844-22851$.

(28) Bazzanella, N.; Checchetto, R.; Miotello, A. Catalytic effect on hydrogen desorption in Nb-doped microcrystalline $\mathrm{MgH}_{2}$. Appl. Phys. Lett. 2004, 85, 5212-5214. 
(29) Checchetto, R.; Bazzanella, N.; Miotello, A.; Maurizio, C.; D’Acapito, F.; Mengucci, P.; Barucca, G.; Majni, G. Nb clusters formation in Nb-doped magnesium hydride. Appl. Phys. Lett. 2005, 87, 061904.

(30) Pelletier, J. F.; Hout, J.; Sutton, M.; Schulz, R.; Sandy, A. R.; Lurio, L. B.; Mochrie, S. G. J. Hydrogen desorption mechanism in $\mathrm{MgH}_{2}-\mathrm{Nb}$ nanocomposites. Phys. Rev. B 2001, 63, 52103.

(31) Jin, S.-A.; Shim, J.-H.; Ahn, J.-P.; Cho, Y. W.; Yi, K.-W. Improvement in hydrogen sorption kinetics of $\mathrm{MgH}_{2}$ with $\mathrm{Nb}$ hydride catalyst. Acta Mater. 2007, 55, 5073-5079.

(32) Macchi, C.; Maurizio, C.; Checchetto, R.; Mariazzi, S.; Ravelli, L.; Egger, W.;

Mengucci, P.; Bazzanella, N.; Miotello, A.; Somoza, A.; Brusa, R.S. Niobium aggregation and vacancy like defect evolution in nanostructured $\mathrm{Nb}$-doped $\mathrm{Mg}$ : Their role in the kinetics of the hydride-to-metal phase transformation. Phys. Rev. B 2012, 85, 214117.

(33) Maurizio, C.; Checchetto, R.; Trapananti, A.; Rizzo, A.; D'acapito, F.; Miotello, A. In situ X-ray absorption spectroscopy-X-ray diffraction investigation of $\mathrm{Nb}-\mathrm{H}$ nanoclusters in $\mathrm{MgH}_{2}$ during hydrogen desorption. J. Phys. Chem. C 2015, 119, 7765-7770.

(34) Kohn, W.; Sham, L. J. Self-Consistent Equations Including Exchange and Correlation Effects. Phys. Rev. 1965, 140, A1133-1138.

(35) Blöchl, P. E. Projector Augmented-Wave Method. Phys. Rev. B: Condens. Matter Mater. Phys. 1994, 50, 17953-17979.

(36) Kresse, G.; Joubert, D. From Ultrasoft Pseudopotentials to the Projector AugmentedWave Method. Phys. Rev. B: Condens. Matter Mater. Phys. 1999, 59, 1758-1775.

(37) Perdew, J. P.; Wang, Y. Accurate and simple analytic representation of the electron-gas correlation energy. Phys. Rev. B: Condens. Matter Mater. Phys. 1992, 45, 13244-13249. 
(38) Vajeeston, P.; Ravindran, P.; Hauback, B. C.; Fjellvåg, H.; Kjekshus, A.; Furuseth, S.; Hanfland, M. Structural stability and pressure-induced phase transitions in $\mathrm{MgH}_{2}$. Phys. Rev. $B$ 73, 2006, 224102.

(39) Vajeeston, P.; Ravindran, P.; Kjekshus, A.; Fjellvåg, H. Pressure-induced structural transitions in $\mathrm{MgH}_{2}$. Phys. Rev. Lett. 89, 2002, 175506.

(40) Park, M. S.; Janotti, A.; Van de Walle, C. G. Formation and Migration of Charged Native Point Defects in $\mathrm{MgH}_{2}$ : First-Principles Calculations. Phys. Rev. B: Condens. Matter Mater. Phys. 2009, 80, 064102.

(41) Bortz, M.; Bertheville, B.; Böttger, G.; Yvon, K. Structure of the High Pressure Phase $\gamma$ $\mathrm{MgH}_{2}$ by Neutron Powder Diffraction. J. Alloys Compd. 1999, 287, L4-L6.

(42) Monkhorst, H. J.; Pack, J. D. Special Points for Brillouin-zone Integrations. Phys. Rev. B 1976, 13, 5188-5192.

(43) Wu, Y.-N.; Zhang, X.-G.; Pantelides, S. T. Fundamental Resolution of Difficulties in the Theory of Charged Point Defects in Semiconductors. Phys. Rev. Lett. 2017, 119, 105501.

(44) Yao, C. L.; Li, J. C.; Gao, W.; Tkatchenko, A.; Jiang, Q. Effective scheme to determine accurate defect formation energies and charge transition levels of point defects in semiconductors. Phys. Rev. B. 2017, 96, 245203.

(45) Yang, J.-H.; Yin, W.-J.; Park, J.-S.; Wei, S.-H. Self-regulation of Charged Defect Compensation and Formation Energy Pinning in Semiconductors. Sci. Rep. 2015, 5, 16977.

(46) Roy, A.; Janotti, A.; Van de Walle, C. G. Effect of Transition-Metal Additives on Hydrogen Desorption Kinetics of $\mathrm{MgH}_{2}$. Appl. Phys. Lett. 2013, 102, 033902.

(47) Lany, S.; Zunger, A. Assessment of Correction methods for the Band-Gap Problem and for Finite-Size Effects in Supercell Defect Calculations: Case Studies for $\mathrm{ZnO}$ and GaAs. Phys. Rev. B 2008, 78, 235101. 
(48) Castleton, C. W. M.; Höglund, A.; Mirbt, S. Density Functional Theory Calculations of Defect Energies Using Supercells. Modelling Simul. Mater. Sci. Eng. 2009, 17, 084003.

(49) Kumar, E. M.; Rajkmal, A.; Thapa, R. Screening based approach and dehydrogenation kinetics for $\mathrm{MgH}_{2}$ : Guide to find suitable dopant using first-principles approach. Sci. Rep. 2017, 7, 15550 .

(50) Hussain, T.; Maark, T. A.; Pathak, B.; Ahuja, R. Improvement in the hydrogen desorption from $\mathrm{MgH}_{2}$ upon transition metal doping: A hybrid density functional calculations. AIP Adv. 2013, 3, 102117.

(51) Isidorssin, J.; Giebels, I. A. M. E.; Arwin, H.; Griessen, R. Optical Properties of $\mathrm{MgH}_{2}$ Measured in Situ by Ellipsometry and Spectrophotometry. Phys rev B 2003, 68, 115112.

(52) Hasnip, P. J.; Refson, K.; Probert, M. I. J.; Yates, J. R.; Clark, S. J.; Pickard, C. J. Density Functional Theory in the Solid State. Philos. T. R. Soc. A. 2014, 372, 1-26.

(53) Hussain, T.; Maark, T. A.; Chakraborty, S.; Ahuja, R. Improvement in the hydrogen desorption from $\beta$ - and $\gamma-\mathrm{MgH}_{2}$ upon transition-metal doping. ChemPhysChem. 2015, 16, $2557-2561$

(54) Lu, Y.-L.; Dong, S.; Zhou, W.; Liu, Y.; Zhao, H.; Wu, P. Semiconducting antiferromagnetism in $\mathrm{MgH}_{2}$ doped with 3d transition metals: A first-principles view. $J$. Magn. Magn. Mater. 2017, 441, 799-805.

(55) Karazhanov, S. Z.; Ulyashin, A. G.; Vajeeston, P.; Ravindran, P. Hydrides as materials for semiconductor electronics. Philos. Mag. 2008, 88, 2461-2476.

(56) Manivasagam, T. G.; Kiraz, K.; Notten, P. H. L. Electrochemical and Optical Properties of Magnesium-Alloy Hydrides Reviewed. Crystals 2012, 2, 1410-1433

(57) Watkins, G.D.; Narayan, and Tan, eds. Defects in Semiconductors 1981 North-Holland, Inc. 


\section{TOC Graphic}
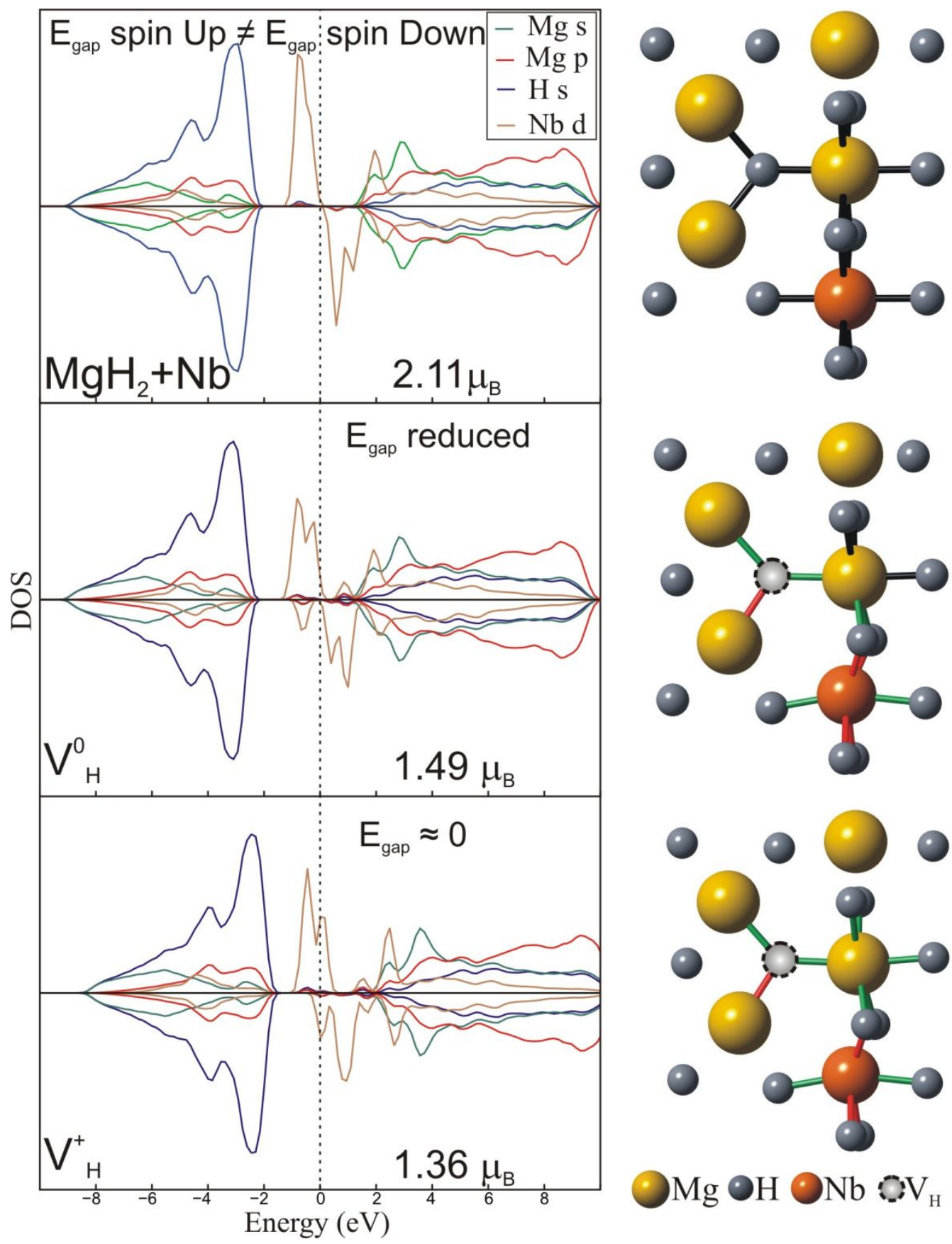

$\mathrm{Mg} \odot \mathrm{H} \odot \mathrm{Nb} \odot \mathrm{V}_{\mathrm{H}}$ 